and those who have sustained brain damage. Patients with physical problems from alcohol abuse would seem to be an obvious area for liaison psychiatry, and if this is a deficiency then we must try to remedy it. As regards the brain damaged patient, there are, I feel, reasons for a lack of interest. These patients usually require considerable expenditure in both time and personnel and cannot be properly catered for in most psychiatric units. The behavioural problems they exhibit make it difficult for them to be cared for in medical wards and the physical handicaps that are present make for difficulties in psychiatric units. There is a great need for money from central funding to be devoted to the development of specialized units specifically designed for the needs of the brain damaged where both physicians and psychiatrists can work together.

Physicians also appear to be concerned over postulated 'mechanisms' in psychosomatics. Epidemiological research is showing possible relationships between psychological factors and physical disease but as yet the actual mechanistic links are poorly understood. Until further research in this field has been carried out it is probably unwise to make only partly justified speculations on the exact links between psyche and soma. Nevertheless the epidemiological findings still stand and offer therapeutic possibilities. When Sir Richard Doll found the link between smoking and lung cancer it was possible to prevent further disease before the exact nature of the carcinogens and their effect on bronchial mucosa was known. Similarly, the exact link between Type A behaviour and coronaries is not fully established, but if more deaths from heart disease can be reduced by changing the behaviour of Type $A$ subjects then this must surely be a significant advance.

In conclusion I feel properly practised liaison psychiatry may well be useful to medicine. However, if we wish the nature of the service we offer to be acceptable then considerably more discussion between psychiatrists and physicians needs to take place.

RefERENCE

'THomas, C. J. (1985) Teaching and experience of liaison psychiatry in psychiatric postgraduates (Correspondence). Bulletin of the Royal College of Psychiatrists, 9, 81-82.

\section{The Sandoz Prize for Gerontological Research}

The International Association of Gerontology (IAG) has awarded the 1985 Sandoz Prize jointly to Sir Martin Roth, Professor of Psychiatry at the University of Cambridge Medical School, and Dr Karl Esser, Professor of Botany at the University of the Ruhr in Bochum (FRG). The award to Sir Martin Roth is a tribute to the work through which he and his team have made a fundamental contribution to psychogeriatric research over many years, creating a foundation for the study of dementia and depression in old age. Professor Esser has been honoured for the genetic and biochemical work of his team, culminating in the development of new models of the ageing process on a molecular basis.

The prize, worth Sw. fr. 20,000 and sponsored by Sandoz, is awarded every second year by the IAG to individuals or teams who have made an outstanding contribution to some aspect of gerontological research.

\section{WHO Programme for Mental Health}

The Department of Psychiatry of the University of Cambridge School of Clinical Medicine has been recognized by the WHO as a National Institution for Research in Mental Disorder of Old Age under its Programme for Mental Health.

\section{'Convulsive Therapy'}

A new quarterly medical journal, Convulsive Therapy, has recently been launched, dedicated to the research and clinical issues in convulsive therapy. Much of the motivation for the journal has come from the surveys and numerous research reports of the Royal College of Psychiatrists and the American Psychiatric Association. The scope of articles includes biologic and sociologic aspects of the treatments, studies of mechanisms, and the ethical and legal concerns which often mark ECT discussions. The editors seek a forum for researchers, students, and practitioners. The inaugural issue was published in April 1985 by Raven Press in New York. Enquiries may be sent to the Editor: Dr Max Fink, State University of New York at Stony Brook, PO Box 457, St James, New York 11780, USA.

\section{3rd AUTP Conference on 'Teaching Dynamic Psychotherapy'}

Following the conferences on 'Teaching Dynamic Psychotherapy' held at University College, Oxford, in 1982 and 1984, the Association of University Teachers of Psychiatry is planning another conference which will be held from 17 to 19 April 1986, again at University College, Oxford. The first conference took a broad overview of the subject and the second concentrated on supervision and issues around personal therapy. Both conferences attracted participants from all over the country and from various professions, all with an interest in training.

Suggestions from both trainers and trainees as to what topics should be included in the 1986 conference and how these might be presented, e.g. lectures, small group activity, panel discussion, demonstrations, would be gratefully received. Offers to contribute to the programme would also be most welcome. Please write to Dr Sidney Bloch, Deparment of Psychotherapy, Warneford Hospital, Oxford OX3 $7 \mathrm{JX}$ in the first instance. Details of the conference will be published in 'Forthcoming Events' at a later stage, but anyone wishing to be placed on the mailing list is asked to write to Dr Bloch.

Mark AVeline SIDNEY BLOCH Conference Organizers 